\title{
Markets for Inventors: Learning-by-Hiring as a Driver of Mobility
}

\author{
Neus Palomeras, Eduardo Melero \\ Department of Business Administration, Universidad Carlos III de Madrid, 28903 Madrid, Spain \\ \{neus.palomeras@uc3m.es, eduardo.melero@uc3m.es\}
}

\begin{abstract}
$\mathrm{H}$ iring away inventors has long been recognized as a way of learning used by innovative firms. This paper claims that the characteristics of the knowledge accumulated by an inventor at his current employer affect what hiring firms can learn from him. The implication is that some inventors are more likely to be hired away than their coworkers. We analyze the relationship between the type of knowledge embodied by inventors working at IBM and their probability of moving. Relying on patent data to track the movement of inventors across firms and to characterize the kind of know-how they hold, we identify the following drivers of inventor mobility: the quality of their work; the complementarity of their knowledge with that of other inventors; and, to a lower extent, their expertise in the firm's core areas in which the firm is not a dominant player. Results confirm the role of knowledge characteristics behind the mobility of research and development personnel and suggest that learning is a relevant force in the market for inventors.
\end{abstract}

Key words: mobility; learning-by-hiring; technology transfer; inventors

History: Received August 25, 2008; accepted September 18, 2009, by Scott Shane, entrepreneurship. Published online in Articles in Advance March 15, 2010.

\section{Introduction}

Leading organizations in high-tech industries are often the source of a great deal of innovative ideas. Apart from directly launching their own innovations, they are also at the origin of some innovations developed either by start-ups created by their own engineers or by firms that hired them away. This is the case of IBM, an industry leader responsible for major innovations in the electronics sector. Some of these innovations were instigated by Glenn Henry, a computer scientist who, after 21 years at IBM, was hired away by Dell Computer Corporation in 1988 to work on product development. Interfirm movements of inventors are not rare. In a recent survey of European inventors responsible for European Patent Office patents, $22.5 \%$ of them reported at least one change in employer in the 6-10 year window following their patent (Giuri et al. 2007).

The literature on innovation has long observed that scientists who leave their employers to join rival firms spread their acquired knowledge (Arrow 1962). Indeed, as Levin et al. (1987) report from a survey of research and development $(R \& D)$ managers, hiring away skilled personnel is quite an effective learning mechanism used by firms. Cassiman and Veugelers (2006), drawing on data from the 1993 Belgian Community Innovation Survey, indicate that $42 \%$ of innovative firms use hiring away to gain access to external technology, and that this is the prevalent strategy for external knowledge acquisition. Almeida and Kogut (1999) find evidence that, in an R\&D intensive sector such as semiconductors, engineer mobility is an important means of spreading ideas between firms in certain geographically restricted areas.

This paper suggests that learning-by-hiring is a significant driver of mobility in high-tech industries. Unlike previous literature, we analyze the process from the point of view of the inventors' knowledge. We hypothesize that the characteristics of the knowledge accumulated by an inventor at his current employer influence what another employer can learn from him. Consequently, inventors embodying knowledge with potential for leverage are relatively more valuable to the market and, therefore, are more likely to leave their current employer.

Previous research has examined learning-by-hiring exclusively from the perspective of the hiring firm. Once hiring away was recognized as a learning mechanism (Arrow 1962, Levin et al. 1987), researchers have focused on analyzing the characteristics of the hiring firm that shape the intensity of learning. For instance, Almeida et al. (2003) find that start-up size negatively impacts the effectiveness of knowledge transfer. Song et al. (2003) and Rosenkopf and Almeida (2003) suggest that learning-by-hiring is especially useful for exploring technologically distant knowledge, regardless of geographical distance. Nevertheless, previous literature has not questioned whether the type of targeted knowledge affects what hiring firms can learn 
from it. The only exception is Zucker et al. (2002), who claim that the involvement of star scientists from universities is a must for any firm wishing to launch innovations based on their discoveries. They find that scientists' quality influences the probability that they will move from university to firms.

Another stream of research has analyzed potential drivers of staff turnover in R\&D firms. A first set of this literature builds on the mechanisms proposed by labor economists as forces behind workers' mobility. ${ }^{1}$ Lewis and Yao (2006) use a matching model to explain the high turnover rates in $R \& D$ intensive sectors. They argue that by allowing freedom of movement, firms are able to attract talented engineers. Fallick et al. (2006) consider innovations as random shocks that increase the value of skilled workers' human capital. Accordingly, mobility mainly represents a reallocation of resources toward firms with the best innovations. A second set of literature focuses on the incentives of the current firm to retain its researchers. These incentives depend on the competition threat posed by a moving researcher, who can replicate and market innovations developed in the firm, eroding its monopoly position. Hence, mobility is the result of weighting the cost of retaining the scientist in terms of wages against the cost posed by competition. Pakes and Nitzan (1983) consider that mobility will only occur in settings with low set-up costs and potential third party competitors. Fosfuri et al. (2001) expect mobility when the hiring firm can use the technology without competing directly with the firm where it originated (i.e., with differentiated products or in other market segments).

This paper contributes to the empirical literature on mobility of R\&D personnel by examining what characteristics of the inventor's knowledge stimulate mobility. We examine this issue in the framework of the computer, semiconductor, and software industries, three highly innovative and patent-intensive sectors. In particular, we identify the trajectory of engineers initially working at IBM, a very active player in these sectors. Patent records help to characterize the career of an inventor as well as the attributes of the knowledge underlying his innovations. We find that the quality of an inventor's work positively influences the probability of leaving his employer. Conversely, the complementarity of his knowledge with that of other inventors, and his core expertise in areas where his employer is not a dominant player, are negatively associated with the probability of moving. These results support the idea that learning is a relevant force behind inventor mobility.

\footnotetext{
${ }^{1}$ Labor economics models usually consider the following drivers of mobility: productivity mismatches between workers and firms (Jovanovic 1979), job shopping for higher wages (Topel and Ward 1992), or external shocks.
}

\section{Theory and Hypotheses}

External sources of knowledge are vital for the innovative capabilities of firms (Cohen and Levinthal 1990). As March and Simon (1958) suggest, many innovations result from borrowing, which can take many forms but always implies knowledge transfer. Knowledge often entails a tacit component that is difficult to specify in a contract and difficult to transfer (Winter 1987). Because this tacit dimension of knowledge is largely embedded in individuals' human capital (Becker 1964), the involvement of creators is a key component of successful transfer (Zucker et al. 2002). There are several formal ways to acquire the external know-how embodied in creators, including hiring them away, taking over their employer, or establishing a technological alliance. Hiring away is a particularly effective means of acquiring and transferring knowledge (Levin et al. 1987), probably because the inventors participate voluntarily. ${ }^{2}$

The acquisition of knowledge from other firms through the hiring of their researchers, known as "learning-by-hiring" (Song et al. 2003) arises from the fact that (1) the tacit knowledge behind innovations resides in the human capital of their inventors, and (2) human capital can be transferred to the new employers. Workers accumulate both tacit and explicit knowledge through their personal experience, through the observation of colleagues or through informal conversations and other information-sharing mechanisms (Rosen 1972, Nonaka 1994). In particular, innovative activities involve a large amount of learning-by-doing and vicarious learning of the noncodifiable scientific knowledge basis underlying inventions (Winter 1987, Hoetker and Agarwal 2007). When a researcher moves, his tacit knowledge is transferred to the new employer if the latter is able to combine the inventor's background with the rest of capabilities of the firm (Cohen and Levinthal 1990). The new employee contributes to enhancing the knowledge base of the hiring firm by drawing on his new employer's resources to create new innovations or further developments of existing ones and by generating spillovers through the interaction with his new coworkers. Rosenkopf and Almeida (2003) confirm that mobility produces knowledge flows between the two firms involved, which increase with the technological distance between them. In a similar vein, Song et al. (2003) findings suggest that hiring away is especially worthwhile when hiring firms enter into new and distant areas.

The potential for knowledge transfer due to researcher mobility may, however, be limited by the embeddedness of such knowledge within team and

\footnotetext{
${ }^{2}$ Conversely, technology-driven takeovers do not guarantee that the inventors stay in the firm after the acquisition (Ernst and Vitt 2000).
} 
organization structures. The value of a researcher's expertise may depend on the continuity of his interaction with the colleagues that participated in the knowledge-generation process. Furthermore, the overall research line trajectory in which a researcher is involved is likely to reside at the firm level (Hoetker and Agarwal 2007). Therefore, mobility of inventors will play a relevant role in the process of knowledge transfer if the scientific knowledge basis that they embody outbalances the role of team and organizational routines in obtaining further innovations.

On another note, incumbent employers of R\&D personnel face a twofold risk if their inventors leave. First, a departing researcher can pose competition to the firm through imitation of the firm's innovations. Second, the firm loses human capital in which it may have invested. ${ }^{3}$ To address these problems, firms can design contracts that deter employees from leaving (Pakes and Nitzan 1983). They can also resort to legal instruments in order to prevent imitation by former employees, including noncompete covenants (Stuart and Sorenson 2003) and patent protection. Whereas courts are often reluctant to enforce the former (Gilson 1999), patents seem more effective. Kim and Marschke (2005) find that mobility, especially at the regional level, positively affects the propensity to patent by firms in high-tech industries. Hence, in sectors with strong patent protection, where firms are safeguarded against imitation, the negative effect posed by a departing researcher is restricted to the loss of valuable knowledge. This loss, however, implies the attrition of the incumbent's generative appropriability, i.e., its ability to develop subsequent innovations building on its current innovations (Ahuja 2007).

Thus, R\&D firms try to learn from inventors with previous experience in other innovative firms, which try to retain them if it is worthwhile. It follows that mobility is driven by the relative value of the inventor's knowledge in the firm with respect to the market. ${ }^{4,5}$ This relative value is determined by (i) the harm suffered by the current employer from its loss, (ii) the potential value that prospective employers can extract from it, and (iii) the possibility of

\footnotetext{
${ }^{3}$ Moen (2005) suggests that scientists pay (at least partly) for the knowledge they accumulate on the job, by accepting wages six percent lower in their first year if they choose an R\&D-intensive career.

${ }^{4}$ An inventor's personal characteristics may also affect his probability of moving. Nevertheless, previous literature has not found strong evidence in this connection. Zucker et al. (2002) and Geuna et al. (2006) find no significant effect of personal characteristics in their analysis of moves from academia. Hoisl (2007) finds that education affects the number of moves.

${ }^{5}$ We understand "market value" as the value of knowledge for any prospective alternative employer, regardless of whether or not it is a direct competitor in the product market. In $\S 4.1$ we discuss this assumption.
}

effectively transferring this knowledge to the new employer. We consider four characteristics of the inventors' knowledge that influence these factors: quality, complementarity, fit within the firm's core areas, and ascription to areas in which the firm is a relevant player. We next develop a set of hypotheses as to how these dimensions of the knowledge embodied by an inventor employed by an innovative firm in a patent-intensive industry affect his probability of moving. Therefore, we focus on the analysis of mobility from firms that may represent an attractive source of knowledge in a setting where knowledge is patent protected, i.e., where learning-by-hiring aims to improve the technological capabilities of the hiring firm (not replication).

\subsection{Quality}

The contribution of an innovation to technological progress is referred to as its quality (Lanjouw and Schankerman 2004). High-quality innovations are backed by highly relevant scientific knowledge and have high expected economic value (Harhoff et al. 1999, Hall et al. 2005). The firm responsible for the innovation can appropriate its direct economic value if it is patented (in a setting where patents are effective). Nevertheless, there is another source of value behind an innovation: its potential to generate future innovations (Hopenhayn and Mitchell 2001). This value emerges from the underlying knowledge basis of the innovation and is difficult to protect. Consequently, it is susceptible to appropriation by other firms (Ahuja 2007), especially when the knowledge is highly embodied in the creator of the innovation and can be captured by hiring him away.

We expect a positive association between the quality of the knowledge basis held by an inventor and interfirm mobility. A researcher will switch employers whenever there is an outside firm where his knowledge can be more profitably devoted to innovative activities and this higher profitability compensates moving costs (Kim and Marskhe 2005, Lewis and Yao 2006). More profitable outside innovation opportunities can be due to the existence of better complementary resources and capabilities (e.g., research environment and facilities, incentives, access to markets), or greater scope for spillovers (i.e., knowledge sharing with new colleagues) outside the current employer. Given a more profitable outside innovation opportunity, the greater the quality of the knowledge, the greater its relative advantage over the internal option. This is because innovation opportunities and knowledge quality have a complementary effect in the generation of value: an innovation opportunity will deliver more value if it is developed by an inventor that holds highly relevant scientific knowledge in the field. As a result, a higher quality of the inventor's 
knowledge basis implies a higher probability of moving, assuming that moving costs remain constant. That is, the existence of better outside innovation opportunities compensates moving costs only for researchers with a sufficiently high-quality knowledge basis. ${ }^{6}$ In line with this idea, Zucker et al. (2002) find that the quality of biotechnology scientists positively affects their probability of moving from the university to a firm.

Нүротнеsis 1. The higher the quality of the inventor's set of knowledge, the more likely he is to move.

\subsection{Complementarity}

An inventor's knowledge is complementary to that of other researchers if the former needs to be combined with the latter to develop its full potential value. Knowledge complementarity may have different sources, mostly related to the use of teams in inventive activities. First of all, innovations frequently result from the combination of different types of knowledge that mutually enhance their value. Given that these complementary pieces of knowledge are usually in the hands of inventors with different backgrounds (Wuchty et al. 2007), innovations are frequently originated in teams. Thus, the know-how of coinventors working in a project may be mutually complementary ex ante. Secondly, team-work in the development of an invention leads, in itself, to the generation of complementary knowledge. If research is organized by assigning interdependent tasks to team members, learning-by-doing will lead to ex post complementary knowledge even if all coworkers start the project with independent backgrounds. In this case, the complementarities generated are specific to the team members involved in the project. Finally, the use of innovation teams leaves knowledge embedded in a complex web of relationships (Van de Ven 1986). In this context, team routines play a key role in the process of value creation, which requires the continued existence of the whole team of coinventors (Hoetker and Agarwal 2007).

An inventor with highly complementary know-how is less likely to move, because his knowledge is particularly difficult to exploit by any alternative employer. ${ }^{7}$ Even if complementarity only emerged from the need

\footnotetext{
${ }^{6}$ Note that our argument does not assume that high-quality knowledge can always be used more profitably outside than inside the current firm. Rather, we argue that, if a better outside innovation opportunity ever arises, it will induce mobility only for inventors holding high-quality knowledge.

${ }^{7}$ In fact, firms often use teams to protect the knowledge behind valuable innovations (Liebeskind 1996). According to Ahuja (2007), this strategy reduces the risk of information leakage through employee mobility and, therefore, enhances the firm's degree of appropriability.
}

to bring together different types of specialized knowledge, regathering a similar complementary combination might be a hard task for the new employer. More importantly, the interdependences and routines developed during the innovation process can make it impossible to fully exploit the knowledge held by an individual inventor without hiring his group of coinventors.

Нyротнеsis 2. The higher the degree of complementarity of the inventor's know-how, the less likely he is to move.

\subsection{Core Expertise}

The core of an innovative firm comprises technological areas typically associated with the firm's comparative advantage. Thus, the innovative activity is especially intensive in these areas, to which the firm devotes many of its human and technical resources. This fact has ambiguous consequences for the potential mobility of inventors working in these areas. On the one hand, higher concentration of inventors in a given area leads to higher overlapping of knowledge. That is, a large amount of researchers working on the development of very close pieces of technology implies very similar knowledge learnt "by doing" (Cohen and Levinthal 1990). Although task specialization moderates this effect, the knowledge acquired through observation and interaction with coworkers in this setting is also subject to a high degree of overlap. Higher knowledge overlap in a technological area implies lower knowledge loss upon an inventor's departure. Consequently, the know-how of an individual inventor from a core area is potentially more useful for the market than for his current employer. On the other hand, research activities that fall within a firm's technological core tend to follow predetermined paths (Song et al. 2003). Because knowledge from core technological areas is an important source of added value, firms are especially likely to build structures to harness it. As a result, core knowledge is deeply embedded in the firm, through wellestablished routines and procedures. This knowledge embeddedness in firm structures hampers knowledge transfer through employee mobility (Hoetker and Agarwal 2007). In sum, the know-how from the firm's core held by an individual inventor is potentially more useful for external employers, but it can not be easily incorporated in their trajectories. Therefore, the direct effect of core expertise on the probability of moving is not clear-cut.

\subsection{Technological Dominance}

An innovative firm has a dominant position in a technological field when it accounts for a high portion of the new technology created in that field. Inventors from fields dominated by their employers embody knowledge that is especially valuable in the market. 
First, the firm's dominant position in a field implies that its researchers have access to a widespread set of the know-how available in the field, which they are able to learn mainly through observation and interaction with coworkers. ${ }^{8}$ Second, field dominance implies relative outside scarcity of the underlying knowledge. The reason is that dominance is expected to be inversely related to the existence of alternative sources of knowledge outside the focal firm.

Interestingly, field dominance may affect the internal value of an inventor's knowledge less intensely than its market value. The internal value of an inventor working in a field that the firm dominates depends on the diffusion of his knowledge within the bounds of the organization. If this field corresponds to an area of the firm characterized by a high degree of overlap among researchers' knowledge, the organization's capabilities will be less dependent on an individual inventor, regardless of the outside scarcity and relative broadness of such knowledge. Conversely, in areas with less overlapping know-how, the absence of external alternatives to replace a relatively broad combination of knowledge will affect its internal and market value to a similar degree. To the extent that there is more knowledge overlap in core areas of the firm, the combination of field dominance and core expertise implies a higher relative outside value of the inventor's knowledge. Thus, core expertise and field dominance will interact positively on inventors' mobility.

In conclusion, knowledge overlap makes an individual inventor from the firm's core potentially more useful for alternative employers. However, core knowledge is also more difficult to transfer. The former effect will override the latter if such core knowledge corresponds to a field that the firm dominates technologically. Therefore, we expect that inventors working in their employers' core will move to other firms when their employer is also a technologically relevant player in the field.

Hypothesis 3. The more expertise an inventor has in the firm's core areas, the more likely he is to move if the employer is a dominant player in these areas. The more expertise an inventor has in the firm's core areas, the less likely he is to move if the employer is not a dominant player in these areas.

\section{Methodology}

\subsection{Data}

We use patent data to track inventors' mobility. Patent documents contain information about the inventors

\footnotetext{
${ }^{8}$ If specialization is low, learning-by-doing also contributes to the acquisition of a relatively broad range of knowledge in dominated fields.
}

as well as the firm that filed the patent, i.e., the assignee, who is normally the inventors' employer. ${ }^{9}$ Thus, by tracking inventors across patents, we can identify their movements between firms (Trajtenberg et al. 2006). We draw on U.S. patent data as compiled in the National Bureau of Economic Research (NBER) Patent Citations Data File (Hall et al. 2001), which comprises all U.S. patents granted between 1970 and 1999.

We focus the analysis on the mobility of inventors working at IBM, a firm that is very active in the computer, semiconductor, and software industries. Its status as major innovator and patentholder and its nonfiring policy ${ }^{10}$ makes it an interesting subject to study as a source of knowledge. The industries in which IBM is active have three important characteristics. First, they are heavily patenting sectors (Ziedonis 2003). This means that patents capture a substantial part of the innovative activity in the industry and, therefore, they are useful for tracking mobility. Second, research in these sectors is cumulative (Ziedonis 2003, Bessen and Maskin 2009), a fact that is indicative of the importance of learning. Third, interfirm mobility of engineers is especially high in these industries (Almeida and Kogut 1999, Fallick et al. 2006).

We select a random sample of inventors who appear in at least one patent assigned to IBM at some point in time between 1970 and 1999 and whose surname begins with the letters $\mathrm{A}-\mathrm{H}$. This sample consists initially of 2,195 inventors. Given our interest in mobility, we consider only inventors whose careers can be tracked with patent data. This implies dropping inventors: (1) who appear only once in the data set, (2) whose only non-IBM patent has an unidentified or noninstitutional assignee, or (3) whose IBM and non-IBM patents all have the same application year. Another issue that needs to be addressed is collaboration between institutions. Results of research collaborations are sometimes assigned to only one of the partners involved. This issue could raise problems of misidentification and artificial mobility in our sample. To avoid them, we eliminate inventors with one IBM patent in between several patents by a different assignee. Analogously, we do not consider as moves the cases in which non-IBM patents appear in the middle of an IBM patenting sequence. Finally, we

\footnotetext{
${ }^{9}$ Exceptions occur when the inventor files a patent by himself (in these cases, the assignee is missing) or when he works as a collaborator in a patent filed by a firm other than his employer (rare).

${ }^{10}$ Until 1992, IBM had a lifetime employment policy for its employees. Then, the firm offered very advantageous severance packages to motivate people to leave. This policy is believed to have motivated the departure of the researchers with better outside opportunities, who benefited from the severance packages and from a new job (Carroll 1994). In any case, both strategies guarantee that the moving inventors left IBM willingly and were not fired.
} 
do not take into account moves to spin-outs. Spinouts are firms started by former employees of the incumbent firm. In these cases, mobility is not motivated by an alternative organization's need to learn but rather by the search for entrepreneurial opportunities (Agarwal et al. 2004). In checking the identity of the hiring firms, we register only one move to an IBM spin-out, which is excluded from the sample. ${ }^{11}$ We also exclude moves originated by the spinoff of some IBM divisions. This process of fine-tuning the identification of movers and stayers reduces the sample to 1,264 inventors, who filed a total of 6,788 patents in IBM during the sample period. We identify 147 movers from IBM, who represent $12 \%$ of the inventors and are responsible for $10 \%$ of IBM patents.

Tracking mobility through patent data has a number of limitations. The most important one is that we can identify a move only if the inventor patents before as well as after switching employers. Covenants not to compete may modify the patenting behavior of a moving inventor and prevent us from observing his move. Another issue is the truncation of inventors' patenting lives. Our sample could suffer both left truncation (we do not know whether they actually start their inventive activity in the first year in which we observe them) and right truncation (we do not know whether there is a move after the last patent we observe). Also, there are complications in identifying the same inventor over a range of patents due to possible spelling differences and the fact that there may be more than one person with the same name. To address this point, we manually correct potential spelling errors and apply a series of filters in order to consider two entries as the same person. ${ }^{12}$ Despite these limitations, previous research has shown the usefulness of patent data to detect inventor mobility on a small scale (Almeida and Kogut 1999, Song et al. 2003) and, more recently, on a large scale (Trajtenberg et al. 2006).

\footnotetext{
${ }^{11}$ We also detect some 17 moves to start-ups whose founders we are unable to track. Although we include them in the final sample, our empirical findings are robust to their exclusion.

${ }^{12}$ The United States Patent and Trademark Office (USPTO) records contain the following information on the inventor: first name, middle name, family name, and city and state where he lives, apart from assignee and patent class of the patented invention. Either when there is a perfect match on the whole name or there are slight variations (i.e., when the middle name appears only as an initial), we require coincidence in assignee, state, or technological subcategory (as defined in Hall et al. 2001). For less clear cases (i.e., when a middle name appearing only as an initial coincides with the initial of different full middle names), we require that two of these elements coincide: assignee, state, or patent class. We also check for time consistency (i.e., we identify two different persons when a full name appears working at two different locations for several years).
}

\subsection{Analysis}

We use event history analysis to estimate the hazard rate that an engineer changes employer during his research life. The inventor's research life is proxied by his patenting life and an employer shift by a change in the assignee of the patent in which he appears as an inventor. The inventor is observed in a sequence of discrete time points that correspond to his patent filings. Consequently, he is at risk only when he patents; otherwise, we are not able to observe his moves.

The result is an unbalanced panel where each inventor contributes $T_{i}$ times, $T_{i}$ being the number of times the inventor is at risk, i.e., the number of patents he files until he leaves (if he is a mover) and the number of patents he files until survival time is censored minus one otherwise (in the last spell, we can not identify whether he stays or he moves). The hazard function takes the form

$$
\lambda_{u}(t+1, Z)=\lambda\left(t, Z_{t}(t) \mid u, \beta\right),
$$

where $\lambda$ is the generic expression for the hazard rate of moving between $t$ and $(t+1)$. The functional form we choose for the baseline hazard function is logarithmic. The term $Z_{t}$ is the vector of time variant explanatory variables observed at $t$. The term $\beta$ is the vector of parameters to be estimated, and $u$ is a random variable that adds unobserved heterogeneity to the model and is distributed independently of $Z$ and $t$. The term $u$ captures the impact of omitted variables, particularly the inventor's personal characteristics (i.e., ability, education, age, gender, marital status, number of children) as well the characteristics of the offer that the inventor receives (i.e., wage offered, firm's reputation, new colleagues, whether move implies change of location, challenges of new job), which are likely to affect the hazard rate but are unknown.

To model the hazard rate in discrete time with time-dependent covariates, we use a binary response model (Yamaguchi 1991). In particular, we use a probit random effects specification in order to account for the individual unobserved heterogeneity caused by individual-specific omitted variables (Jenkins 2005). ${ }^{13}$

\subsection{Explanatory Variables}

The dependent variable that reflects mobility is a dummy variable taking value 0 if the inventor does not move in the subsequent period he is at risk, i.e., if the next patent is assigned to IBM, and 1 otherwise. ${ }^{14}$

\footnotetext{
${ }^{13}$ The alternative in order to take unobserved heterogeneity into account, the logit fixed effects specification, would only consider noncensored individuals, i.e., inventors who move. In any case, the Hausman test does not reject the null hypothesis of consistency of the random effects model.

${ }^{14}$ Note that the last patent at IBM in censored individuals and the patents out of IBM in noncensored individuals do not contribute as observations (in these cases, they are not at risk in next period).
} 
Independent variables are described next. Note that they are computed in a cumulative way up to each of the inventor's risk periods.

Quality. The extent to which a patent is valuable is usually proxied by the number of citations it receives from subsequent patents, which reflects its contribution to technological progress. Given that patents must cite the related prior art, the number of citations received is considered an indicator of the technological relevance of a given patent. Jaffe et al. (2000) find that the number of citations received by a patent is correlated with the inventors' perception of its technological value and with its economic value. Several studies corroborate the positive correlation between citations received and objective measures of economic value (Harhoff et al. 1999, Hall et al. 2005). Thus, in order to capture the quality of an inventor's knowledge at a given point of time, we draw on the citations received by the patents he has filed up to that moment. In particular, we compute the average standardized citations received. ${ }^{15,16}$

Complementarity. In his study of firms' appropriability, Ahuja (2007) uses the average number of inventors on a given firm's patents to measure the firm's degree of labor division. Analogously, we rely on the number of inventors listed in the patent document in order to capture the degree of complementarity of the knowledge of the inventors working on the innovation. This is a good measure of the team that actually worked on the innovation, given that all relevant contributors must be stated in the patent document if the property right is to be enforced (Klee 1998). Although the number of coinventors is a variable that does not capture the internal processes developed during the project, we expect it to be strongly correlated with the number of interactions and, therefore, with the potential complementarities developed. In particular, we compute the mean number of coinventors per patent in the inventor's set of patents up to a given point in time.

Core. Following the rationale of Song et al. (2003) to identify core technology areas of large firms, we consider that an innovation falls within IBM's core

\footnotetext{
${ }^{15}$ Standardization is necessary because patents granted in different years have different time spans over which to receive citations. Following Hall et al. (2001), we standardize the citations each patent receives by the mean citations received by the population of patents applied in its same year and technological category.

${ }^{16}$ Alternatively, we could use the total number of (standardized) citations received. Such measure, however, is highly correlated with the number of patents filed by the inventor, an important control variable in our analysis. By using the average citations received, we avoid multicollinearity problems and, at the same time, we are able to disentangle the effect of knowledge quality from that of research intensity (captured by the number of patents).
}

if its patent class coincides with some of the timevariant highest frequent classes in the firm's portfolio. Given that IBM patents are very dispersed across patent classes, we define core classes as those that represent more than $2.5 \%$ of the firm's portfolio in a given five-year time window. ${ }^{17}$ To measure the inventor's experience in IBM's core areas in each of his risk periods, we build a variable that gathers the percentage of his patents that falls within the firm's core up to that time.

Field dominance. Our purpose is to develop a measure of the relative importance of a specific firm in a specific technological field. Thus, we adopt the methodology used by Shane (2001). To assess the role of university inventions in a given technological field, he measures the share of patents assigned to universities in each field and year. In a similar vein, we use the share of IBM patents filed in a given technological subcategory and time window with respect to the total number of USPTO patents in that subcategory and interval. In this way, we capture the relative importance of IBM innovations in a given area. We then compute, for each inventor and point in time, the mean dominance of IBM in the technological subcategories in which he has patented up to that point.

\subsection{Control Variables}

Number of patents. This variable tracks the sequence of patents filed by the inventor in IBM (the baseline time hazard). At the organizational level, patent counts is considered a good indicator of the inputs to the innovative process (i.e., R\&D efforts), but not of the value of the results (Trajtenberg 1990). Analogously, an inventor's number of registered patents can be considered a good proxy of the intensity of his research activity. Previous empirical studies find that inventors' intensity of research activity has a negative or insignificant effect on mobility (Zucker et al. 2002, Geuna et al. 2006, Hoisl 2007). Because research activity could also be correlated with the characteristics of the inventor's knowledge, the number of patents is an important control variable in our analysis. Therefore, we introduce the number of patents filed by the inventor with IBM up to each point of time.

Tenure. This variable reflects the years that the inventor has worked in the firm. It has been extensively noted in the labor economics literature that, as tenure increases, the probability of job change diminishes drastically, basically because people get established at their job and gain firm-specific human capital (Topel and Ward 1992). We proxy tenure with the difference in years between the application year

\footnotetext{
${ }^{17}$ In IBM, no single patent class gathers the $10 \%$ share of the firm's portfolio that Song et al. (2003) suggest for the definition of core. For this reason, we choose the more restrictive threshold of $2.5 \%$.
} 
of the first IBM patent filed by the inventor and the application year of each of his subsequent patents.

Technological area. The specific area in which the inventor patents may affect his external value and other variables such as productivity or quality. We create a set of dummy variables that gather the percentage of the inventor's patents that falls in each of the technological categories defined by Hall et al. (2001) on the basis of patent classes.

Self-citations received. A patent can receive citations from another patent owned by the same firm. As previous research has suggested, self-citations may reflect differently the value of the innovation than external citations, as their respective inclusion in the patent document may obey to different motivations (Hall et al. 2005). We take this into account by controlling for the ratio of self-citations. In particular, we measure this variable as the mean percentage of self-citations that the inventor receives in his set of patents.

Dispersion of citations received. To accurately reflect the quality of the inventor's work, it is necessary to take into account the dispersion of the citations he receives across patents. As a measure of quality, we use the average citations that an inventor receives per patent, and we control for the number of patents in the analysis. Nevertheless, two inventors with the same mean quality per patent and number of patents can be valued very differently by the market according to how dispersed their citations are across patents. For this reason, we also control for the standard deviation of the citations received by the inventor's set of patents.

Region. Almeida and Kogut (1999) provide evidence of regional differences in the intensity of labor market flows for engineers. Furthermore, they show that mobility is mostly intraregional. Because IBM research facilities are located at various points in the United States and worldwide, the existence of an active labor market, and the concentration of firms in each region will affect the probability that an inventor receives an external offer as well as the probability that he accepts it. We use the state that appears in the patent as the inventor's address (New York, California, Texas, Minnesota, Vermont, and non-United States) to create a set of dummy variables that capture in which IBM facilities the inventor previously worked.

Time. It is necessary to control for time effects in order to take account of potential changes across years that could influence the prospects of mobility. These changes can be either environmental (industry or macroeconomic issues), or IBM-related (e.g., human resources practices and its leadership position in the sector). We use patent application years to take account of time effects. Also, to control for cohort effects, we introduce the earliest year (grouped in intervals) in which the inventor patented at IBM.

Previous mobility. In general, workers who have moved in the past are more likely to switch employers again (Topel and Ward 1992). In particular, inventors who arrived to IBM from another company may be more mobile than those who have developed their whole career in IBM. This may be because they have different personal characteristics, more diverse social networks, or simply a weaker commitment to the firm. To control for previous mobility, we introduce a dummy variable that captures whether the inventor patented outside IBM before enrolling with the firm.

\section{Results}

Descriptive statistics and correlations for the independent variables at inventor level are shown in Tables 1 and 2. Table 3 displays the coefficient estimates for different specifications of the model presented in Equation (1). Table 4 reports the corresponding marginal effects computed at the mean of each explanatory variable, keeping the rest of independent variables at their means as well. ${ }^{18}$ Because continuous variables are log transformed, the marginal effect of each one reflects the percentage increase in the probability of moving when its value increases twofold (i.e., by 100\%) from its mean. Finally, Table 5 presents average marginal effects, i.e., the mean of the marginal effects predicted for all the observations of the sample. Although the mean marginal effects are more informative than the marginal effects at the mean, the latter approach is more common in the literature (Hoetker 2007). In our study, however, the figures presented in Tables 4 and 5 are relatively similar. The unit of observation is the inventor each time he patents at IBM, excluded the last time that a censored inventor does. Each observation captures (i) the characteristics of the inventor's stock of knowledge at this point of time, and (ii) whether he files his next patent with IBM or with a different firm. In all but one specification, the proportion of the total error variance accounted for by the random effect is very small in magnitude and not statistically significant.

All specifications include the time invariant control variables, i.e., the inventor's year of entry into the sample and the previous mobility dummy, as well as the time variant controls, i.e., the patent year, the inventor's tenure, and the technological categories and regions where he has patented. The estimated probability of moving in a given interpatent spell for an inventor with all the variables at their mean, is approximately $1.8 \%$.

\footnotetext{
${ }^{18}$ Note that the marginal effect of each variable depends on the values of the rest of variables of the model. We choose the mean values of the original variables at the inventor level as the most meaningful point to evaluate the marginal effects.
} 
Table 1 Descriptive Statistics at the Inventor Level

\begin{tabular}{lllllc}
\hline Variables & Mean & Std. dev. & Median & Min & Max \\
\hline Number of patents per inventor & 3.19 & 3.17 & 2 & 1 & 44.50 \\
Mean of standardized citations received per patent & 1.70 & 1.71 & 1.27 & 0 & 16 \\
Mean number of coinventors per patent & 3.94 & 2.11 & 3.59 & 1 & 23 \\
Percentage of patents in the core per inventor & 0.241 & 0.356 & 0 & 0 & 1 \\
Mean degree of scarcity of the inventor's patents & 0.047 & 0.032 & 0.048 & 0.0006 & 0.105 \\
Standard deviation of the citations received by inventor & 1.04 & 1.56 & 0.503 & 0 & 14.21 \\
Mean percentage of self-citations received per patent & 0.181 & 0.189 & 0.144 & 0 & 1 \\
Tenure & 3.90 & 3.17 & 2.82 & 1 & 19 \\
Percentage of patents in category 1 (chemical) & 0.089 & 0.243 & 0 & 0 & 1 \\
Percentage of patents in category 2 (computers and communications) & 0.557 & 0.462 & 0.75 & 0 & 1 \\
Percentage of patents in category 4 (electrical and electronic) & 0.229 & 0.365 & 0 & 0 & 1 \\
Percentage of patents in category 5 (mechanical) & 0.090 & 0.246 & 0 & 0 & 1 \\
Percentage of patents in category 6 (others) & 0.035 & 0.149 & 0 & 0 & 1 \\
Percentage of patents in region 1 (New York) & 0.346 & 0.476 & 0 & 0 & 1 \\
Percentage of patents in region 2 (California) & 0.109 & 0.312 & 0 & 0 & 1 \\
Percentage of patents in region 3 (Texas) & 0.106 & 0.308 & 0 & 0 & 1 \\
Percentage of patents in region 4 (Vermont and Minnesota) & 0.127 & 0.334 & 0 & 0 & 1 \\
Percentage of patents in region 5 (United States, missing state) & 0.263 & 0.440 & 0 & 0 & 1 \\
Percentage of patents in region 6 (outside United States) & 0.131 & 0.338 & 0 & 0 & 1 \\
Entry year at IBM & 1987 & 7.37 & 1989 & 1968 & 1998 \\
Move from IBM & 0.116 & 0.320 & 0 & 0 & 1 \\
\hline
\end{tabular}

Note. $N=1,264$ inventors

The time effect is represented by the number of times the inventor has patented. The coefficient of this variable is significantly negative, meaning that the more patents an inventor files in the firm, the lower his hazard of moving. This negative effect is consistently robust across specifications, although the intensity is reduced when we control for patent quality. According to Table 5, a 100\% increase in the number of patents decreases the probability of moving, on average, by $1.2 \%$. Alternatively, a $10 \%$ increase from its mean value, i.e., a shift from 3.2 to 3.5 patents, would decrease the probability by approximately $0.1 \%$, according to Table 4 . This result is consistent with the argument posed by Hoisl (2007) that departure probability decreases with the number of patents filed by an inventor with a given firm, because it reflects a good match between firm and employee.

The coefficient of Quality is positive and significant, supporting the first hypothesis: the greater the quality of an inventor, the more likely he is to move. This positive effect is robust across specifications and its average magnitude amounts to $1.1 \%$ when the mean citations received per patent doubles. The variable that captures the Complementarity of the inventor's knowledge displays a significantly negative effect that confirms the second hypothesis, i.e., that the more complementary the inventor's know-how, the less likely he is to move. Specifically, the probability of moving is, on average, $0.9 \%$ lower if the number of coinventors per patent increases twofold.

The variables Core and Technological Dominance present nonsignificant effects when considered independently. When the interaction between Core and Technological Dominance is introduced, the effect of Core is significantly negative for values of Dominance close to zero. The interaction between these two variables is positive and significant at $10 \%$. However, the joint effect of the Core variable plus

Table 2 Correlations at the Inventor Level

\begin{tabular}{|c|c|c|c|c|c|c|c|c|}
\hline Variables & (1) & (2) & (3) & (4) & (5) & (6) & (7) & $(8)$ \\
\hline (1) Number of patents & - & & & & & & & \\
\hline (2) Mean standardized citations per patent & 0.1230 & - & & & & & & \\
\hline (3) Mean coinventors per patent & -0.0144 & 0.0779 & - & & & & & \\
\hline (4) Percentage of core patents & $0.1075^{*}$ & $-0.0859^{*}$ & -0.0399 & - & & & & \\
\hline (5) Mean scarcity per patent & -0.0002 & $-0.1804^{*}$ & $-0.0938^{*}$ & $0.6350^{*}$ & - & & & \\
\hline (6) Mean $\%$ of self-citations per patent & $0.0960^{*}$ & $0.0556^{*}$ & $0.0604^{*}$ & $0.1314 *$ & $0.1170^{*}$ & - & & \\
\hline (7) Standard deviation of citations & $0.2703^{*}$ & $0.6697^{*}$ & $0.0513^{*}$ & $-0.0638^{*}$ & $-0.1671^{*}$ & 0.0185 & - & \\
\hline (8) Tenure & $0.5383^{*}$ & $0.1738^{*}$ & -0.0834 & -0.0384 & $-0.0888^{*}$ & $0.0457^{*}$ & $0.2856^{*}$ & \\
\hline (9) Entry year & $-0.1823^{*}$ & $-0.1210^{*}$ & $0.2551^{*}$ & $0.1511^{*}$ & $0.1147^{*}$ & -0.0119 & $-0.1172^{*}$ & $-0.6265^{*}$ \\
\hline
\end{tabular}

${ }^{*} p<0.001$. 
Table 3 Probit Random Effects on the Probability of an Inventor's Move: Coefficient Estimates

\begin{tabular}{|c|c|c|c|c|c|}
\hline Variables & Specification 1 & Specification 2 & Specification 3 & Specification 4 & Specification 5 \\
\hline Core & & & & $\begin{array}{c}-0.049 \\
(0.117)\end{array}$ & $\begin{array}{r}-0.453^{*} \\
(0.250)\end{array}$ \\
\hline Dominance & & & & $\begin{array}{c}2.594 \\
(2.320)\end{array}$ & $\begin{array}{c}-0.295 \\
(2.800)\end{array}$ \\
\hline Core $*$ Dominance & & & & & $\begin{array}{c}6.893^{*} \\
(3.675)\end{array}$ \\
\hline Complementarity & & & $\begin{array}{r}-0.159 * \\
(0.083)\end{array}$ & $\begin{array}{c}-0.164^{* *} \\
(0.083)\end{array}$ & $\begin{array}{c}-0.163^{* *} \\
(0.084)\end{array}$ \\
\hline Quality & & $\begin{array}{c}0.167^{*} \\
(0.093)\end{array}$ & $\begin{array}{l}0.192^{* *} \\
(0.093)\end{array}$ & $\begin{array}{c}0.195^{* *} \\
(0.093)\end{array}$ & $\begin{array}{c}0.203^{* *} \\
(0.094)\end{array}$ \\
\hline Self-citations & & $\begin{array}{c}-1.242^{* * *} \\
(0.265)\end{array}$ & $\begin{array}{c}-1.226^{* * *} \\
(0.264)\end{array}$ & $\begin{array}{c}-1.243^{* * *} \\
(0.267)\end{array}$ & $\begin{array}{c}-1.245^{* * *} \\
(0.265)\end{array}$ \\
\hline Citation dispersion & & $\begin{array}{r}-0.059^{*} \\
(0.035)\end{array}$ & $\begin{array}{r}-0.061^{*} \\
(0.035)\end{array}$ & $\begin{array}{r}-0.062^{*} \\
(0.035)\end{array}$ & $\begin{array}{r}-0.062^{*} \\
(0.035)\end{array}$ \\
\hline Number of patents & $\begin{array}{c}-0.278^{* * *} \\
(0.071)\end{array}$ & $\begin{array}{c}-0.212^{* * *} \\
(0.074)\end{array}$ & $\begin{array}{c}-0.215^{* * *} \\
(0.074)\end{array}$ & $\begin{array}{c}-0.221^{* * *} \\
(0.074)\end{array}$ & $\begin{array}{c}-0.214^{* * *} \\
(0.074)\end{array}$ \\
\hline Tenure & $\begin{array}{c}0.111 \\
(0.100)\end{array}$ & $\begin{array}{c}0.116 \\
(0.103)\end{array}$ & $\begin{array}{c}0.127 \\
(0.103)\end{array}$ & $\begin{array}{c}0.128 \\
(0.104)\end{array}$ & $\begin{array}{c}0.133 \\
(0.104)\end{array}$ \\
\hline Previous mobility & $\begin{array}{c}0.220^{*} \\
(0.129)\end{array}$ & $\begin{array}{c}0.202 \\
(0.131)\end{array}$ & $\begin{array}{c}0.197 \\
(0.132)\end{array}$ & $\begin{array}{c}0.202 \\
(0.132)\end{array}$ & $\begin{array}{c}0.206 \\
(0.132)\end{array}$ \\
\hline Category 1 & $\begin{array}{r}0.693^{*} \\
(0.363)\end{array}$ & $\begin{array}{c}0.710^{*} \\
(0.374)\end{array}$ & $\begin{array}{c}0.717^{* *} \\
(0.376)\end{array}$ & $\begin{array}{c}0.703^{*} \\
(0.375)\end{array}$ & $\begin{array}{c}0.715^{*} \\
(0.374)\end{array}$ \\
\hline Category 2 & $\begin{array}{c}0.490 \\
(0.334)\end{array}$ & $\begin{array}{c}0.546 \\
(0.347)\end{array}$ & $\begin{array}{c}0.519 \\
(0.349)\end{array}$ & $\begin{array}{c}0.374 \\
(0.375)\end{array}$ & $\begin{array}{c}0.477 \\
(0.377)\end{array}$ \\
\hline Category 4 & $\begin{array}{c}0.481 \\
(0.345)\end{array}$ & $\begin{array}{c}0.465 \\
(0.354)\end{array}$ & $\begin{array}{c}0.433 \\
(0.357)\end{array}$ & $\begin{array}{c}0.372 \\
(0.363)\end{array}$ & $\begin{array}{c}0.454 \\
(0.364)\end{array}$ \\
\hline Category 5 & $\begin{array}{c}0.534 \\
(0.366)\end{array}$ & $\begin{array}{c}0.498 \\
(0.375)\end{array}$ & $\begin{array}{c}0.490 \\
(0.378)\end{array}$ & $\begin{array}{c}0.492 \\
(0.378)\end{array}$ & $\begin{array}{c}0.567 \\
(0.379)\end{array}$ \\
\hline Region 1 & $\begin{array}{c}-0.054 \\
(0.112)\end{array}$ & $\begin{array}{c}-0.007 \\
(0.113)\end{array}$ & $\begin{array}{c}-0.008 \\
(0.113)\end{array}$ & $\begin{array}{c}-0.020 \\
(0.114)\end{array}$ & $\begin{array}{c}-0.017 \\
(0.114)\end{array}$ \\
\hline Region 2 & $\begin{array}{c}0.356^{* * *} \\
(0.125)\end{array}$ & $\begin{array}{c}0.380^{* * *} \\
(0.126)\end{array}$ & $\begin{array}{c}0.370^{* * *} \\
(0.127)\end{array}$ & $\begin{array}{c}0.360^{* * *} \\
(0.127)\end{array}$ & $\begin{array}{c}0.342^{* * *} \\
(0.128)\end{array}$ \\
\hline Region 3 & $\begin{array}{c}0.223 \\
(0.139)\end{array}$ & $\begin{array}{c}0.204 \\
(0.139)\end{array}$ & $\begin{array}{c}0.183 \\
(0.140)\end{array}$ & $\begin{array}{c}0.168 \\
(0.141)\end{array}$ & $\begin{array}{c}0.164 \\
(0.141)\end{array}$ \\
\hline Region 4 & $\begin{array}{c}-0.025 \\
(0.131)\end{array}$ & $\begin{array}{c}0.002 \\
(0.134)\end{array}$ & $\begin{array}{c}-0.000 \\
(0.134)\end{array}$ & $\begin{array}{c}-0.016 \\
(0.135)\end{array}$ & $\begin{array}{c}-0.005 \\
(0.136)\end{array}$ \\
\hline Region 5 & $\begin{array}{l}0.214^{* * *} \\
(0.108)\end{array}$ & $\begin{array}{c}0.212^{*} \\
(0.110)\end{array}$ & $\begin{array}{c}0.208^{*} \\
(0.110)\end{array}$ & $\begin{array}{c}0.204^{*} \\
(0.110)\end{array}$ & $\begin{array}{c}0.200^{*} \\
(0.110)\end{array}$ \\
\hline $\begin{array}{l}\text { Entry time } \\
\text { Patent time }\end{array}$ & $\begin{array}{l}\text { Included } \\
\text { Included }\end{array}$ & $\begin{array}{l}\text { Included } \\
\text { Included }\end{array}$ & $\begin{array}{l}\text { Included } \\
\text { Included }\end{array}$ & $\begin{array}{l}\text { Included } \\
\text { Included }\end{array}$ & $\begin{array}{l}\text { Included } \\
\text { Included }\end{array}$ \\
\hline Constant & $\begin{array}{c}-1.970^{* * *} \\
(0.605)\end{array}$ & $\begin{array}{c}-2.008^{* * *} \\
(0.635)\end{array}$ & $\begin{array}{c}-1.900^{* * *} \\
(0.640)\end{array}$ & $\begin{array}{l}-1.907^{* * *} \\
(-0.639)\end{array}$ & $\begin{array}{c}-1.929 * * * \\
(0.643)\end{array}$ \\
\hline Observations & 5,670 & 5,670 & 5,670 & 5,670 & 5,670 \\
\hline Number of individuals & 1,264 & 1,264 & 1,264 & 1,264 & 1,264 \\
\hline Wald chi2 & $74.50^{* *}$ & $97.11^{* * *}$ & $100.17^{* * *}$ & $101.18^{* * *}$ & $104.28^{* * *}$ \\
\hline Rho & 0.000 & 0.003 & $7.21 \mathrm{e}-06$ & 0.000 & $6.08 \mathrm{e}-07$ \\
\hline
\end{tabular}

Note. Dependent variable: Move from IBM.

${ }^{*} p<0.10,{ }^{* *} p<0.05,{ }^{* * *} p<0.01$ denotes significant levels of the coefficients.

the interaction is not significantly greater than zero at the maximum value of Technological Dominance. ${ }^{19}$ Therefore, Hypothesis 3 is only partially supported. Inventors with more experience in Core areas with low

\footnotetext{
${ }^{19}$ Because Technological Dominance is a continuous variable, we tested the significance of the joint effect of Core plus the interaction at the minimum and maximum level of Dominance. Although in the first case, the effect is significant at the $7 \%$ level, in the second case, the effect is not significant.
}

IBM Dominance have lower probability of leaving the firm. As the Technological Dominance of IBM increases, the negative effect of Core on mobility diminishes. However, there does not exist a level of Dominance high enough in our sample to make the effect of Core significantly positive. Figure 1 displays the conditional effects plot for Core at different values of Technological Dominance (its minimum, mean and maximum levels). The rest of the variables are at their mean 
Table 4 Probit Random Effects on the Probability of an Inventor's Move: Marginal Effects at the Mean

\begin{tabular}{|c|c|c|c|c|c|}
\hline Variables & Specification 1 & Specification 2 & Specification 3 & Specification 4 & Specification 5 \\
\hline Core & & & & $\begin{array}{c}-0.002 \\
(0.005)\end{array}$ & $\begin{array}{r}-0.020^{*} \\
(0.011)\end{array}$ \\
\hline Dominance & & & & $\begin{array}{c}0.113 \\
(0.102)\end{array}$ & $\begin{array}{r}-0.013 \\
(0.122)\end{array}$ \\
\hline Core $*$ Dominance & & & & & $\begin{array}{r}0.300^{*} \\
(0.163)\end{array}$ \\
\hline Complementarity & & & $\begin{array}{c}-0.007^{* *} \\
(0.003)\end{array}$ & $\begin{array}{c}-0.007^{* *} \\
(0.004)\end{array}$ & $\begin{array}{c}-0.007^{* *} \\
(0.003)\end{array}$ \\
\hline Quality & & $\begin{array}{c}0.008^{* *} \\
(0.004)\end{array}$ & $\begin{array}{c}0.008^{* *} \\
(0.003)\end{array}$ & $\begin{array}{c}0.009 * * \\
(0.003)\end{array}$ & $\begin{array}{l}0.009 * * * \\
(0.003)\end{array}$ \\
\hline Self-citations & & $\begin{array}{c}-0.059^{* * * *} \\
(0.013)\end{array}$ & $\begin{array}{c}-0.054^{* * * *} \\
(0.012)\end{array}$ & $\begin{array}{c}-0.054^{* * * *} \\
(0.012)\end{array}$ & $\begin{array}{c}-0.054^{* * * *} \\
(0.012)\end{array}$ \\
\hline Citation dispersion & & $\begin{array}{r}-0.003^{*} \\
(0.002)\end{array}$ & $\begin{array}{r}-0.003^{*} \\
(0.001)\end{array}$ & $\begin{array}{r}-0.003^{*} \\
(0.001)\end{array}$ & $\begin{array}{r}-0.003^{*} \\
(0.001)\end{array}$ \\
\hline Number of patents & $\begin{array}{c}-0.016^{* * * *} \\
(0.005)\end{array}$ & $\begin{array}{c}-0.010^{* *} \\
(0.004)\end{array}$ & $\begin{array}{c}-0.009 * * \\
(0.004)\end{array}$ & $\begin{array}{c}-0.010^{* *} \\
(0.004)\end{array}$ & $\begin{array}{c}-0.009^{* *} \\
(0.004)\end{array}$ \\
\hline Tenure & $\begin{array}{c}0.006 \\
(0.006)\end{array}$ & $\begin{array}{c}0.005 \\
(0.005)\end{array}$ & $\begin{array}{c}0.006 \\
(0.005)\end{array}$ & $\begin{array}{c}0.006 \\
(0.005)\end{array}$ & $\begin{array}{c}0.006 \\
(0.005)\end{array}$ \\
\hline
\end{tabular}

Note. Dependent variable: Move from IBM.

${ }^{*} p<0.10,{ }^{* *} p<0.05,{ }^{* * *} p<0.01$ denotes significant levels of the coefficients.

(except for the controls of time and region, which are set at their mode). The chart shows the positive effect on the probability of moving of an increase in Core expertise when Technological Dominance is at its maximum. Despite the steep slope of the dotted line, the imprecision of the estimation of the interaction makes this effect not significant. For values of Dominance at its mean or below, Core displays a negative effect. Figure 1 also shows that the probability of moving increases with Dominance if the Core patents represent more than $4.3 \%$ of the inventor's portfolio (the 32nd percentile of the sample). Figure 2 helps to interpret the marginal effect of the interaction correctly. As Norton et al. (2004) note, the sign, magnitude, and significance of the marginal effect varies across observations. This figure displays the interaction effect for all observations, which is positive for all of them, but it is not always significant.

\subsection{Some Robustness Checks}

Some assumptions in the foregoing analysis may be problematic. First, we do not take account of knowl-

Table 5 Probit Random Effects on the Probability of an Inventor's Move: Average Marginal Effects

\begin{tabular}{|c|c|c|c|c|c|}
\hline Variables & Specification 1 & Specification 2 & Specification 3 & Specification 4 & Specification 5 \\
\hline Core & & & & $\begin{array}{c}-0.003 \\
(0.007)\end{array}$ & $\begin{array}{r}-0.025^{*} \\
(0.014)\end{array}$ \\
\hline Dominance & & & & $\begin{array}{c}0.145 \\
(0.130)\end{array}$ & $\begin{array}{c}-0.016 \\
(0.156)\end{array}$ \\
\hline Core $*$ Dominance & & & & & $\begin{array}{r}0.384^{*} \\
(0.208)\end{array}$ \\
\hline Complementarity & & & $\begin{array}{r}-0.009^{*} \\
(0.005)\end{array}$ & $\begin{array}{r}-0.009^{*} \\
(0.005)\end{array}$ & $\begin{array}{r}-0.009^{*} \\
(0.005)\end{array}$ \\
\hline Quality & & $\begin{array}{c}0.009^{*} \\
(0.005)\end{array}$ & $\begin{array}{c}0.011^{* *} \\
(0.005)\end{array}$ & $\begin{array}{c}0.011^{* *} \\
(0.005)\end{array}$ & $\begin{array}{c}0.011^{* *} \\
(0.005)\end{array}$ \\
\hline Self-citations & & $\begin{array}{c}-0.070^{* * *} \\
(0.015)\end{array}$ & $\begin{array}{c}-0.069 * * * \\
(0.015)\end{array}$ & $\begin{array}{c}-0.069 * * * \\
(0.015)\end{array}$ & $\begin{array}{c}-0.069^{* * * *} \\
(0.015)\end{array}$ \\
\hline Citation dispersion & & $\begin{array}{r}-0.003^{*} \\
(0.002)\end{array}$ & $\begin{array}{r}-0.003^{*} \\
(0.002)\end{array}$ & $\begin{array}{r}-0.003^{*} \\
(0.002)\end{array}$ & $\begin{array}{r}-0.003^{*} \\
(0.002)\end{array}$ \\
\hline Number of patents & $\begin{array}{c}-0.016^{* * *} \\
(0.004)\end{array}$ & $\begin{array}{c}-0.012^{* * *} \\
(0.004)\end{array}$ & $\begin{array}{c}-0.012^{* * *} \\
(0.004)\end{array}$ & $\begin{array}{c}-0.012^{* * *} \\
(0.004)\end{array}$ & $\begin{array}{c}-0.012^{* * *} \\
(0.004)\end{array}$ \\
\hline Tenure & $\begin{array}{c}0.006 \\
(0.006)\end{array}$ & $\begin{array}{c}0.006 \\
(0.006)\end{array}$ & $\begin{array}{c}0.007 \\
(0.006)\end{array}$ & $\begin{array}{c}0.007 \\
(0.006)\end{array}$ & $\begin{array}{c}0.007 \\
(0.006)\end{array}$ \\
\hline
\end{tabular}

Note. Dependent variable: Move from IBM.

${ }^{*} p<0.10,{ }^{* *} p<0.05,{ }^{* * *} p<0.01$ denotes significant levels of the coefficients. 
Figure 1 Conditional Effect Plot: Core Expertise for Different Levels of Scarcity (All Other Variables at Their Mean)

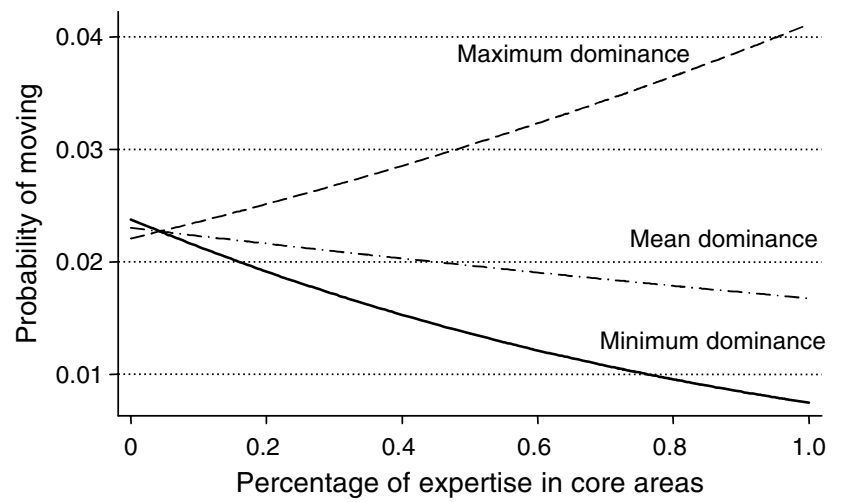

edge depreciation over time. Second, we do not distinguish whether hiring firms are competitors or noncompetitors of the focal firm. We address both issues below.

From the methodological point of view, one might question the contribution to an inventor's current knowledge of the innovations carried out many years ago. If technological knowledge is subject to a high rate of depreciation, its characteristics will be more accurately measured by taking into account only the innovations from the last few years. To explore this issue, we develop an alternative measure for each characteristic that includes information only from the patents filed within the 10 years prior to the focal observation. The results are qualitatively similar to those obtained for the measures that consider the full history of inventors.

A second potentially controversial point of our analysis is that we pool together all kinds of moves, independently of whether the hiring firm is a direct IBM competitor or not. We deliberately do so because our theoretical framework focuses on the characteristics of an inventor's knowledge that make him more likely to move, regardless of the nature of the hiring firm. Nonetheless, strategic issues could affect the

Figure 2 Interaction Effects After Probit

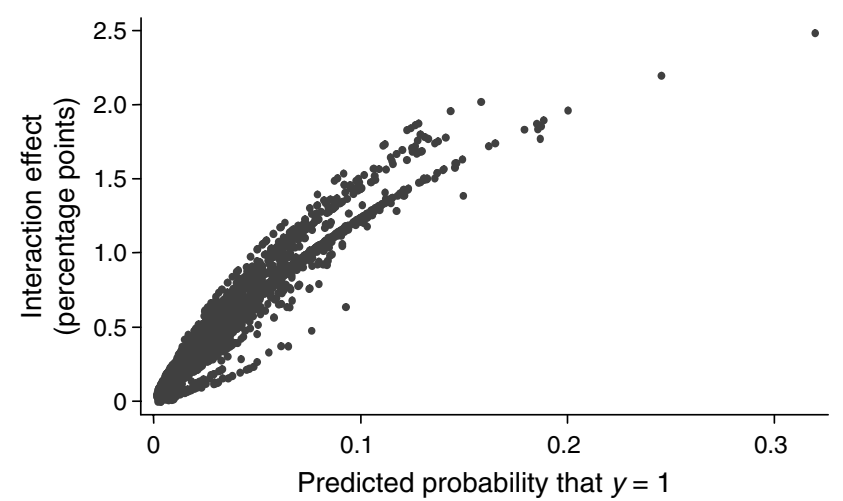

value of hiring (and retaining) the inventor when the poaching firm is a direct competitor of IBM. If knowledge characteristics such as quality interact with these strategic issues, their effect on mobility may differ according to the nature of the hiring firm. To address this point, we retrieve patent data on the hiring firms of the 147 moving inventors in our sample and classify them as competitors and noncompetitors according to their technological overlap with IBM. ${ }^{20}$ Then, we perform a multinomial probit analysis where we consider moving to a competitor (53 cases) and moving to a noncompetitor (94 cases) as two different competing risks. Results do not show any significant difference in the effect of knowledge characteristics on the probability of moving to competitors versus moving to noncompetitors.

\section{Discussion and Conclusion}

In this paper, we analyze the moves of inventors between employers under the perspective of learningby-hiring. The study focuses on the effect of different characteristics of the knowledge accumulated by the inventors over their inventive career on their probability of changing employer. The effect of these attributes depends on their relative value for the current employer with respect to the market. If prospective employers value a particular feature more than the incumbent employer does, it contributes positively to the probability that the inventor moves. In particular, we predict that (i) the quality of the inventor's innovations, (ii) the complementarity of his knowledge with that of other inventors, and (iii) his expertise in the core areas of the firm in which it is a dominant player, have a relevant impact on the relative value of the inventor's knowledge in the current firm versus the market.

We examine empirically the moves of inventors from IBM, a large firm active in the computer, semiconductor, and software industries. Consistent with predictions, we find that the probability of an inventor moving is negatively affected by the extent to which his knowledge is complementary and by his expertise in core areas of the firm in which it is not a technologically dominant player. Conversely, an increase in the mean level of quality of the inventor's work positively affects his probability of moving. However, our findings do not support the prediction that greater core expertise in areas that the firm technologically dominates increases the probability of moving. Our rationale is based on the argument that the complementary effect of technological dominance and internal overlap on mobility should compensate

\footnotetext{
${ }^{20}$ In particular, we classify as competitors those firms that share some core technological area with IBM.
} 
the negative effect of high firm-level embeddedness of core knowledge. The results suggest that this latter effect is more persistent than what we have assumed. Indeed, the negative impact of firm-level embeddedness on knowledge transfer leads to lower mobility of inventors from the core. This is only partially compensated by the technological dominance of the focal firm.

From the point of view of knowledge management, these findings support the idea that learning is a relevant driver of hiring away. Previous literature has pointed out that firms use hiring away as a mechanism to learn from the knowledge developed at other firms and embodied in their creators. The findings of this paper offer a new perspective on this topic and suggest that firms hire away the inventors from whom they can actually learn. Taken together, the characteristics of the knowledge embodied in the moving inventors indicate that hires are motivated by learning. First, the support for the first hypothesis suggests that hiring firms are especially interested in learning high-quality knowledge. Among the many instances of inventors that could better exploit their knowledge outside their current employer, only those with potential to generate superior value move. Furthermore, we find that inventors with core knowledge are less likely to move unless their current employer is also a dominant player in the field. This result underlines the role of firm-level knowledge embeddedness associated with core areas. When knowledge is more embedded in the firm structures, mobility of workers decreases, because learning-by-hiring becomes more difficult. Finally, the result that complementary knowledge hinders mobility indicates that hiring firms are actually seeking in the inventor the ability to seize and transfer the know-how behind an innovation, and this diminishes with the degree of complementarity of his knowledge.

All in all, results suggest learning as a driver of hiring away. However, taken in isolation, some results are consistent with alternative interpretations. This is the case of high-quality inventors as more likely movers. One could argue that the market actually values the ability to develop high-quality innovations. If the incumbent employer has better information on the inventors' abilities than the market, patent quality can work as a signal that reduces this informative advantage (Spence 1973, Greenwald 1986). Therefore, holders of high-quality patents should be more mobile because they are more visible to the market than inventors with equivalent ability but with lowerquality patents. The asymmetric information story could also fit the result that inventors with higher complementary knowledge are less mobile. Indeed, the more complementary the knowledge of an inventor, the weaker the signal that his patents send to the market. However, this rationale cannot explain the finding that inventors from core areas that the firm does not technologically dominate are less likely to move. If anything, problems of information asymmetry that hamper mobility should be lower in these areas, given the relative abundance of inventors with similar skills.

This research is also relevant from the perspective of human resource management at innovative firms. Findings suggest that researchers holding highquality knowledge are the ones most likely to leave their current employer. Even if the firm has mechanisms to appropriate their current innovations, their departure may harm the firm's ability to innovate in the future. Therefore, innovative firms trying to prevent this knowledge loss should implement mechanisms to dissuade such inventors from defecting, and to minimize the impact of defections that occur. ${ }^{21}$ One such mechanism is the use of research teams, as suggested by our result on complementary knowledge. That is, inventors working with a larger number of coinventors are less likely to leave the firm. Thus, promoting complementary research even above organizationally efficient levels is an approach to make it less attractive for other firms to poach in-house inventors. Another such mechanism is establishing structures that harness inventors' ideas, energy, and motivations. Lindholm-Dahlstrand (2001) reports that start-ups are generally formed by researchers whose projects have been rejected by their employers. Analogously, we find some evidence that frustrated projects could also play some role in interfirm mobility of inventors. Results reveal that the percentage of self-citations received by an inventor's patent negatively affect his probability of moving. If self-citations received reflect the continuity of a given research line inside the firm, this result suggests that movers' projects receive less internal attention. In a similar vein, our finding that inventors with more patents are less likely to leave may reflect that inventors who find useful resources and structures to develop their ideas accumulate firm-specific skills that make them stay. Further research should establish to what extent researchers are motivated to leave by the rejection of their ideas or by the lack of structures to exploit them.

The research presented in this article is subject to several limitations. First of all, patent data does not allow scrutinizing the internal processes at work during the innovation project. This compels us to rely in an imperfect measure of complementarity, such as

\footnotetext{
${ }^{21}$ Note that, in the long run, it is not necessarily optimal to restrict inventor's mobility. As noted by Lewis and Yao (2006), allowing inventors to move may enable the firm to hire more talented scientists and to provide them with stronger incentives. These advantages, however, must be traded off against the reduced incentives for the employer to invest in the human capital of its workers.
} 
the average number of coinventors. Furthermore, the exact contribution of each coinventor to a given innovation cannot be assessed with our data, so that we need to assume that innovation characteristics relate to knowledge characteristics equally for all coinventors. Secondly, the findings of this paper arise from the study of a specific firm in a specific sector, i.e., the leader of a sector characterized by cumulative innovation and patenting. Even if hiring away appears as an important mechanism of external knowledge acquisition in innovative firms, it is likely that the patterns of innovation, appropriability, and learning differ from industry to industry. Moreover, IBM nonfiring policy has typically kept its nonvoluntary turnover rate at low levels, so that drivers of mobility other than learning-by-hiring probably play a minor role in our study. Consequently, we should be cautious about generalizing the results. Further research is needed to assess whether the same drivers of mobility apply to other industries as well as to nonleading firms. Despite these limitations, this analysis contributes to the understanding of the role of knowledge flows and mobility. Further research should also aim at exploring this phenomenon from other angles. We should understand what kind of firms rely on learning-byhiring and how they fit this knowledge into their internal knowledge structure. The consequences of mobility for innovative activity in the source firms should also be examined.

\section{Acknowledgments}

The authors are grateful to Bruno Cassiman, Marco Giarratana, Reinhilde Veugelers, and the three anonymous referees for their valuable suggestions. The authors also thank seminar participants at the Economic Change Workshop in London, Universitat Autònoma de Barcelona, European Policy for Intellectual Property seminar at Sant'Anna School in Pisa, and the workshop of Economics and Management of Innovation at KULeuven. Financial support under Grants SEJ2006-01731 and CSD200616 (Spanish Government) and S2007/HUM-0413 (Madrid Regional Government) is gratefully acknowledged. Neus Palomeras also acknowledges support from the Steunpunt O\&O (Flemish government) at KULeuven. The usual disclaimers apply.

\section{References}

Agarwal, R., R. Echambadi, A. Franco, M. B. Sarkar. 2004. Knowledge transfer through inheritance: Spin-out generation, development and survival. Acad. Management J. 47(4) 501-522.

Ahuja, G. 2007. When Atlas shrugged: Preemption, complexity and division of labor in a theory of appropriability. Working paper, University of Michigan Business School, Ann Arbor.

Almeida, P., B. Kogut. 1999. Localization of knowledge and the mobility of engineers in regional networks. Management Sci. 45(7) 905-917.

Almeida, P., G. Dokko, L. Rosenkopf. 2003. Start-up size and the mechanisms of external learning: Increasing opportunity and decreasing ability? Res. Policy 32(2) 301-315.
Arrow, K. 1962. Economic welfare and the allocation of resources for innovation. R. Nelson, ed. The Rate and Direction of Inventive Activity: Economic and Social Factors. Princeton University Press, Princeton, NJ, 609-625.

Becker, G. 1964. Human Capital. Columbia University Press, New York.

Bessen, J., E. Maskin. 2009. Sequential innovation, patents and imitation. RAND J. Econom. 40(4) 611-635.

Carroll, P. 1994. Big Blues: The Unmaking of IBM. Crown Publishers, New York.

Cassiman, B., R. Veugelers. 2006. In search of complementarity in the innovation strategy: Internal R\&D and external technology acquisition. Management Sci. 52(1) 68-82.

Cohen, W., D. Levinthal. 1990. Absorptive capacity: A new perspective on learning and innovation. Admin. Sci. Quart. 35(1) 128-152.

Ernst, H., J. Vitt. 2000. The influence of corporate acquisitions on the behaviour of key inventors. RED Management 30(2) 105-119.

Fallick, B., C. A. Fleischmann, J. B. Rebitzer. 2006. Job hopping in Silicon Valley: Some evidence concerning the microfoundations of a high technology cluster. Rev. Econom. Statist. 88(3) 472-481.

Fosfuri, A., M. Motta, T. Ronde. 2001. Foreign direct investment and spillovers through workers' mobility. I. Internat. Econom. 53(1) 205-222.

Geuna, A., G. Crespi, L. Nesta. 2006. Labour mobility of academic inventors. Career decision and knowledge transfer. SPRU Working Paper 139, Science and Technology Policy Research, University of Sussex, Brighton, East Sussex, UK.

Gilson, R. J. 1999. The legal infrastructure of high technology industrial districts: Silicon Valley, Route 128 and covenants not to compete. New York Univ. Law Rev. 74(3) 575-629.

Giuri, P., M. B. Mariani, G. Crespi, D. Francoz, A. Gambardella, W. Garcia-Fontes, A. Geuna, et al. 2007. Inventors and invention processes in Europe: Results from the PatVal-EU survey. Res. Policy 36(8) 1107-1127.

Greenwald, B. C. 1986. Adverse selection in the labour market. Rev. Econom. Stud. 53(3) 325-347.

Hall, B. H., A. Jaffe, M. Trajtenberg. 2001. The NBER Patent Citations Data File: Lessons, insights and methodological tools. NBER Working Paper 8498, National Bureau of Economic Research, Cambridge, MA.

Hall, B. H., A. Jaffe, M. Trajtenberg. 2005. Market value and patent citations. RAND J. Econom. 36(1) 16-38.

Harhoff, D., F. Narin, F. Scherer, K. Vopel. 1999. Citation frequency and the value of patented inventions. Rev. Econom. Statist. 81(3) 511-515.

Hoetker, G. 2007. The use of logit and probit models in strategic management research: Critical issues. Strategic Management J. 28(4) 331-343.

Hoetker, G., R. Agarwal. 2007. Death hurts, but it isn't fatal: The post-exit diffusion of knowledge created by innovative companies. Acad. Management J. 50(2) 446-467.

Hoisl, K. 2007. Tracing mobile inventors-The causality between inventor mobility and inventor productivity. Res. Policy 36(5) 619-636.

Hopenhayn, H., M. Mitchell. 2001. Innovation variety and patent breadth. RAND J. Econom. 32(1) 152-166.

Jaffe, A. B., M. Trajtenberg, M. S. Fogarty. 2000. Knowledge spillovers and patent citations: Evidence from a survey of inventors. Amer. Econom. Rev. 90(2) 215-218.

Jenkins, S. P. 2005. Survival analysis. Unpublished manuscript, Institute for Social and Economic Research, University of Essex, Colchester, UK. Retrieved March 2, 2010, http://www.iser. essex.ac.uk/files/teaching/stephenj/ec968/pdfs/ec968lnotesv6.pdf. 
Jovanovic, B. 1979. Job matching and the theory of turnover. J. Political Econom. 87(5) 972-990.

Kim, J., G. Marschke. 2005. Labor mobility of scientists, technological diffusion, and the firm's patenting decision. RAND J. Econom. 36(2) 298-317.

Klee, M. 1998. The case of the omitted inventor. IEE Engrg. Medicine Biol. 17(3) 110

Lanjouw, J. O., M. Schankerman. 2004. Patent quality and research productivity: Measuring innovation with multiple indicators. Econom. J. 114(495) 441-465.

Levin, R. C., A. K. Klevorick, R. R. Nelson, S. G. Winter. 1987. Appropriating the returns from industrial research and development. Brookings Papers on Econom. Activity 18(3) 783-832.

Lewis, T. R., D. Yao. 2006. Innovation, knowledge flow, and worker mobility. Working paper. Retrieved March 2, 2010, http://www.people.hbs.edu/dyao/LewisYaoMobility.pdf.

Liebeskind, J. P. 1996. Knowledge, strategy, and the theory of the firm. Strategic Management J. 17 93-107.

Lindholm-Dahlstrand, A. 2001. Entrepreneurial origin and spin-off performance: A comparison between corporate and university spin-offs. P. Moncada-Paterno-Castello, A. Tübke, R. Migče, T. Botella-Yaquero, eds. Corporate and Research-Based SpinOffs: Drivers for Knowledge-Based Innovation and Entrepreneurship. European Commission Technical Report EUR-19903-EN, Institute for Prospective Technological Studies, Seville, Spain.

March, J., H. Simon. 1958. Organizations. John Wiley \& Sons, New York.

Moen, J. 2005. Is mobility of technical personnel a source of R\&D spillovers? J. Labor Econom. 23(1) 81-114.

Nonaka, I. 1994. A dynamic theory of organizational knowledge creation. Organ. Sci. 5(1) 14-37.

Norton, E. C., H. Wang, C. Ai. 2004. Computing interaction effects and standard errors in Logit and Probit models. Stata J. 4(2) 154-167.

Pakes, A., S. Nitzan. 1983. Optimum contracts for research personnel, research employment and the establishment of "rival" enterprises. J. Labor Econom. 1(4) 345-365.
Rosen, S. 1972. Learning and experience in the labor market. J. Human Res. 7(3) 326-342.

Rosenkopf, L., P. Almeida. 2003. Overcoming local search through alliances and mobility. Management Sci. 49(6) 751-766.

Shane, S. 2001. Technology regimes and new firm formation. Management Sci. 47(9) 1173-1190.

Song, J., P. Almeida, G. Wu. 2003. Learning-by-hiring: When is mobility more likely to facilitate interfirm knowledge transfer? Management Sci. 49(4) 351-365.

Spence, M. 1973. Job market signaling. Quart. J. Econom. 87(3) 355-374.

Stuart, T., O. Sorenson. 2003. Liquidity events and the geographic distribution of entrepreneurial activity. Admin. Sci. Quart. 48(2) 175-201.

Topel, R., M. Ward. 1992. Job mobility and the careers of young men. Quart. J. Econom. 107(2) 439-479.

Trajtenberg, M. 1990. A penny for your quotes: Patent citations and the value of innovation. RAND J. Econom. 21(1) 172-187.

Trajtenberg, M., G. Shiff, R. Melamed. 2006. The names game: Harnessing inventors' patent data for economic research. NBER Working Paper 12479, National Bureau of Economic Research, Cambridge, MA.

Van de Ven, A. 1986. Central problems in the management of innovation. Management Sci. 32(4) 590-607.

Winter, S. 1987. Knowledge and competence as strategic assets. D. Teece, ed. The Competitive Challenge-Strategies for Industrial Innovation and Renewal. Ballinger, Cambridge, MA, 159-184.

Wuchty, S., B. F. Jones, B. Uzzi. 2007. The increasing dominance of teams in production of knowledge. Science 316(5827) 1036-1039.

Ziedonis, H. R. 2003. Patent litigation in the U.S. semiconductor industry. W. A. Cohen and S. A. Merrill, eds. Patents in the Knowledge-Based Economy. National Academies Press, Washington, DC, 180-215.

Zucker, L. G., M. R. Darby, M. Torero. 2002. Labor mobility from academe to commerce. J. Labor Econom. 20(3) 629-660.

Yamaguchi, K. 1991. Event History Analysis. Sage, London. 